\title{
Neoplasms of Anal Canal and Perianal Skin
}

\author{
Daniel Leonard, M.D., ${ }^{1}$ David Beddy, M.D., ${ }^{1}$ and Eric J. Dozois, M.D. ${ }^{1}$
}

\section{ABSTRACT}

Tumors of the anus and perianal skin are rare. Their presentation can vary and often mimics common benign anal pathology, thereby delaying diagnosis and appropriate and timely treatment. The anatomy of this region is complex because it represents the progressive transition from the digestive system to the skin with many different co-existing types of cells and tissues. Squamous cell carcinoma of the anal canal is the most frequent tumor found in the anal and perianal region. Less-frequent lesions include Bowen's and Paget's disease, basal cell carcinoma, melanoma, and adenocarcinoma. This article aims to review the clinical presentation, diagnostic evaluation, and treatment options for neoplasms of the anal canal and perianal skin.

KEYWORDS: Anal squamous-cell carcinoma, anal basal-cell carcinoma, anal melanoma, anal Paget's disease, anal Bowen's disease, anal adenocarcinoma

Objectives: On completion of this article, the reader should be able to understand the diagnosis, treatment, and prognosis of tumors of the anal margin and canal.

Tumors of the anus are infrequent neoplasms of the digestive tract. The most frequent tumor of the anal canal and perianal skin is squamous cell carcinoma (SCC). Although its treatment has not evolved significantly in the last decade, a major breakthrough has been the discovery of human papillomavirus (HPV) infection as a major etiology of the disease and its possible prevention through the use of novel vaccines. Other less common neoplasms of the anal canal and skin are basal cell carcinoma, melanoma, and adenocarcinoma. Bowen's disease and Paget's disease are in situ carcinomas and are the precursor lesions of SCC and adenocarcinoma, respectively. The uncommon occurrence, and nonspecific clinical presentation of these lesions, often leads to misdiagnosis and a delay in appropriate treatment. In this article, we review the current knowledge about etiology, classification, diagnosis, and treatment of neoplasms of the anal canal and perianal skin.

\section{ANATOMY}

The anal canal is defined as the caudal part of the large intestine extending from the anorectal ring to the anal verge and is $\sim 3$ to $5 \mathrm{~cm}$ in length. Outside of the anal verge lies the anal margin, also referred to as the perianal skin, which commonly encompasses a radius of $5 \mathrm{~cm}$. The anal verge can be identified visually as the part of the anal canal remaining closed when the buttocks are gently retracted. The upper anal canal is lined by columnar tissue that transitions into squamous epithelium at the dentate line. The dentate line, identified by the termination of the anal columns, lies 1 to $2 \mathrm{~cm}$ above the anal verge. $^{1,2}$

The arterial supply of the anus is derived from branches of the superior rectal artery, the inferior rectal branch of the pudendal artery, and branches of the median sacral artery. The venous drainage of the anal canal is divided into two patterns. Above the dentate
${ }^{1}$ Division of Colon and Rectal Surgery, Mayo Clinic, Rochester, Minnesota.

Address for correspondence and reprint requests: Eric J. Dozois, M.D., Division of Colon and Rectal Surgery, Mayo Clinic, Gonda 9 South, 200 First St. SW, Rochester, MN 55905 (e-mail: Dozois. eric@mayo.edu).
Anorectal Disease; Guest Editor, Gerald A. Isenberg, M.D.

Clin Colon Rectal Surg 2011;24:54-63. Copyright (C) 2011 by Thieme Medical Publishers, Inc., 333 Seventh Avenue, New York, NY 10001, USA. Tel: +1(212) 584-4662.

DOI: http://dx.doi.org/10.1055/s-0031-1272824.

ISSN 1531-0043. 
line, via the terminal branches of the superior rectal vein into the inferior mesenteric vein and portal system, and below the dentate line via the inferior rectal vein into the pudendal vein passing to the internal iliac vein.

The lymphatic drainage of the upper anal canal and internal anal sphincter drain upwards into the submucosal and intramural lymphatics of the rectum that then drain to perirectal nodes of the mesorectum and ultimately to the inferior mesenteric nodes. The lower anal canal and external anal sphincter lymphatics drain downwards via perianal plexuses into vessels that drain into the external inguinal lymph nodes. The lymphatics of the puborectalis drain into the internal iliac nodes. It must be noted that there is considerable variation in the lymphatic drainage and that there are numerous connections between lymphatics at various levels of the anal canal. ${ }^{1,3}$

\section{CLASSIFICATION}

\section{Anal Canal Tumors}

The current World Health Organization classification of tumors of the anus defines both intraepithelial and invasive tumors. ${ }^{4}$ Anal intraepithelial neoplasia (AIN) is considered a precursor to anal SCC and is graded by the same system used for its cervical counterpart. ${ }^{5}$ It is defined by the presence of cellular and nuclear abnormalities without a breach of the epithelial basement membrane. Invasive carcinomas are classified as SCC, adenocarcinoma, mucinous adenocarcinoma, small cell carcinoma, and undifferentiated carcinoma.

\section{Anal Margin Tumors}

Tumors of the anal margin include squamous cell carcinoma as well as its precursor AIN. AIN 3 is synonymous to carcinoma in situ and was formerly known as Bowen's disease. Other anal margin tumors include giant condyloma (verrucous carcinoma), basal cell carcinoma, and Paget's disease. Verrucous carcinoma is a rare variant of squamous cell carcinoma and is also known as the tumor of Buschke-Lowenstein who described it in 1925. Paget's disease of the anal margin is an intraepithelial adenocarcinoma and is similar to that in the breast.

\section{INCIDENCE}

In the United States, the incidence of SCC has increased with 3500 new cases in 2001, 3990 in 2005, and a recent estimate of 4200 cases per year. ${ }^{6,7}$ Worldwide, an increasing incidence has also been observed in the last 30 to 40 years, particularly in developed countries. The incidence is estimated between 0.2 to $1.4 / 100,000$ with a slight female predominance. ${ }^{1,2,7-9}$ In men who practice anal-receptive sexual intercourse, the incidence of anal cancer is much higher (up to 35 per 100,000) and those who are human immunodeficiency virus (HIV) positive have twice the risk of those who are not. ${ }^{10}$ Other factors strongly associated with anal SCC include the number of sexual partners; coexistence of sexually transmitted diseases; history of cervical, vulvar, or vaginal carcinoma; and use of immunosuppression after solid organ transplantation.

\section{ETIOLOGY}

HPV is the most important causative factor in the development of anal SCC. Other predisposing factors include immunosuppression and cigarette smoking. In most cases, anal infection with HPV is sexually transmitted and the risk for cancer is increased in patients with a history of receptive anal intercourse in women and homosexual activity in men. ${ }^{11}$ In some cases, a history of receptive anal intercourse is absent suggesting that genital HPV infection causes a field change throughout the perineum. In a process that is identical to cervical intraepithelial neoplasia, HPV causes anal intraepithelial neoplasia that progresses from low-grade to high-grade dysplasia and ultimately to invasive cancer. Once highgrade dysplasia becomes established in the anal canal there is rarely regression of the lesions. Although data on progression to invasive cancer is not available, two studies with follow-up spanning nearly 20 years have shown that $\sim 5 \%$ of AIN 3 lesions undergo malignant change. ${ }^{12,13}$ Some subtypes of HPV, notoriously type 16 and 18 , are strongly associated with malignant transformation. ${ }^{14}$ Cell-mediated immunity appears to be important in the host response that prohibits HPV from establishing a prolonged presence. Support for this finding comes from the observation that anal cancer rates are increased in HIV-positive patients and patients that undergo renal transplant where cell-mediated immunity is suppressed. ${ }^{15,16}$ Cigarette smoking has been implicated as a risk factor for the development of anal cancer in several case-control studies. The risk is increased 5-fold compared with controls. ${ }^{17,18}$ It was considered for many years that chronic irritation of the perineum and anal canal predisposed to development of anal cancer, but it now appears that benign anal lesions are no longer thought to contribute to the development of anal cancer. ${ }^{11}$

\section{ANAL CANAL TUMORS}

\section{Squamous Cell Carcinoma}

Patients typically present with bright red bleeding, pain, and/or a palpable mass. ${ }^{1,2} \mathrm{SCC}$ of the anal canal can also be a fortuitous finding in up to $20 \%$ of cases. ${ }^{19}$ When a clinically suspicious lesion is identified, diagnosis relies 


\section{Table 1 TNM Anus Staging}

\begin{tabular}{ll}
\hline Primary tumor (T) \\
TX & Primary tumor cannot be assessed \\
T0 & No evidence of primary tumor \\
Tis & Carcinoma in situ (Bowen's disease, high-grade \\
& squamous intraepithelial lesion (HISL), AIN II-III \\
T1 & Tumor $2 \mathrm{~cm}$ or less in greatest dimension \\
T2 & Tumor more than $2 \mathrm{~cm}$ but not more than $5 \mathrm{~cm}$ in \\
& greatest dimension \\
T3 & Tumor more than 5 cm in greatest dimension \\
T4 & Tumor of any size invades adjacent organ(s), e.g., \\
& vagina, urethra, bladder (direct invasion of rectal \\
& wall, perirectal skin, subcutaneous tissue, or \\
Regional lymph nodes (N) \\
NX & Regional lymph nodes cannot be assessed \\
N0 & No regional lymph node metastasis \\
N1 & Metastasis in perirectal lymph nodes(s) \\
N2 & Metastasis in unilateral internal iliac and/or unilateral \\
& inguinal lymph node(s) \\
N3 & Metastasis in perirectal and inguinal lymph nodes \\
& and/or bilateral internal iliac and/or inguinal \\
Distant metastases (M) & No distant metastasis \\
M0 & Distant metastasis \\
M1 & lymph nodes \\
\hline Adapted from & Edge et a
\end{tabular}

Adapted from Edge et al. ${ }^{8}$

on cytologic or histologic confirmation. The staging system most widely used is the classification endorsed by the American Joint Committee on Cancer, $7^{\text {th }}$ edition, 2010 (Table 1). ${ }^{8}$ The size of the primary tumor is frequently assessed by clinical examination. It is often necessary to conduct an examination under anesthesia as these patients may present with pain and to ascertain fixation to local structures relaxation of the anal canal musculature is necessary. Indeed, many patients will have been initially treated as having benign anal pathology such as anal fissure or hemorrhoids.

\section{STAGING INVESTIGATIONS}

Locoregional staging investigations include endoanal ultrasound, computed tomography (CT), or magnetic resonance imaging (MRI) of the pelvis. These imaging modalities can delineate tumor dimensions and show invasion into the external sphincter and perirectal tissues. The advantage of MRI over CT is its ability to delineate the soft tissue planes more clearly and demonstrate involvement of structures such as the male urethra or the vagina. Anal cancer metastasizes via the lymphatic system and less commonly by the hematogenous route and synchronous inguinal lymph node disease in $\sim 10 \%$ of patients. ${ }^{20}$ Of all patients presenting with palpable inguinal lymphadenopathy, only $50 \%$ of these will turn out to be metastatic; it is recommended that all palpable nodes be evaluated by fine-needle aspiration biopsy. ${ }^{21}$

Most patients (75-90\%) have no clinical signs of inguinal metastasis at the time of initial presentation and patients with localized disease that later develop inguinal nodal disease do so in the ipsilateral groin. ${ }^{20}$ On this background, some have suggested routine sentinel lymph node (SLN) evaluation as a staging technique in patients that do not have palpable nodes. A systematic review of five published series evaluating the outcome of SLN biopsy of nonenlarged inguinal nodes in patients with anal cancer has been published. ${ }^{22}$ In this review, including 83 patients, the success in identifying the SLN was $90 \%$; however, only $21 \%$ of sentinel nodes contained tumor.

Another technique under investigation is the use of positron emission tomography- (PET-) CT to improve detection of nonenlarged positive nodes. A study of 27 patients undergoing initial PET-CT then followed by SLN biopsy in patients with clinically normal inguinal nodes has been reported. ${ }^{23}$ Here PET-CT suggested inguinal metastasis in 7 patients; however, subsequent histologic evaluation confirmed metastasis in only 3 of the 7 patients, giving the radiologic technique a positive predictive value of $43 \%$. It is remains unclear whether or not elective lymphadenectomy of nodes containing micrometastasis confers advantage over delayed lymphadenectomy performed when inguinal nodes become clinically palpable. At the present time, it is generally accepted that evaluation of groin nodes with biopsy is not made unless they are either clinically palpable or enlarged greater than $10 \mathrm{~mm}$ on CT or MRI. ${ }^{24}$ Systemic staging should also be completed with adequate imaging of the liver and lungs to exclude metastasis.

\section{CHEMORADIATION TREATMENT OF ANAL CANAL SOUAMOUS CELL CARCINOMA}

The historical treatment of anal canal SCC was by abdominoperineal resection of the anal canal and rectum with the formation of an end colostomy. The 5year survival rate was around 50 to $70 \%$, with involvement of pelvic lymph nodes reducing this to below $20 \% .{ }^{25}$ With the works of Nigro et al in the 1970s, chemoradiotherapy became first-line treatment. ${ }^{26}$ In the initial randomized study, radiotherapy was combined with 5-FU and mitomycin-based chemotherapy in a neoadjuvant setting and compared with surgery alone. The presence of a complete pathologic response with no residual tumor in several patients led some centers to adopt chemoradiotherapy as definitive treatment. Since the 1970s, other studies have demonstrated the efficacy of the chemoradiotherapy regimen as a curative treatment modality and have also examined methods to reduce local toxicity of the treatment. The large randomized British trial (ACT I) conducted by the United Kingdom Coordinating Committee for 
Cancer Research (UKCCCR), compared radiotherapy in combination with 5-FU and mitomycin versus radiotherapy alone, demonstrating improved results in patients receiving chemoradiotherapy. ${ }^{27}$ With the chemoradiotherapy regime, complete response is obtained in $70 \%(64-86 \%)$ of patients and the 5-year overall survival rate is $75 \%(66-92 \%){ }^{27,28}$

Locoregional failure rates vary between $16 \%$ and 33\%. ${ }^{27,29-31}$ Approximately one half of patients with locoregional failure are considered to have persistent disease after chemoradiotherapy and the other half to be true local recurrences. ${ }^{19,32}$ Of the true local recurrences, $87 \%$ occur during the first 2 years of follow-up. The superiority of chemoradiotherapy regimes using mitomycin versus $5-\mathrm{FU}$ or cisplatin or regimes based on radiotherapy alone have been confirmed by other large trials including the European Organization for Research on Treatment of Cancer (EORTC) group. ${ }^{30}$ Recently, published long-term follow-up of the UKCCCR study (median 13 years) have confirmed the initial findings of the superiority of chemoradiotherapy over radiotherapy alone in terms of local control and cancer-related deaths. For every 100 patients treated with chemoradiotherapy, there is an expected 25.3 fewer patients with locoregional relapse and 12.5 fewer anal cancer deaths compared with 100 patients given radiotherapy alone. ${ }^{28}$

Ongoing studies are examining techniques to improve local control with less toxicity. Mitomycin is associated with a 60\% incidence of serious (grade 3-4) hematologic, pulmonary, renal toxic events and also hemolytic-uremic syndrome. ${ }^{33}$ Cisplatin has also been used in anal canal SCC chemoradiotherapy regimes producing less toxicity than mitomycin with reasonable response rates. The first high-level evidence study, RTOG 98-11, found a higher rate of colostomy formation in the cisplatin group (19\% vs 10\%) compared with the mitomycin group, suggesting response rates may not be as good. ${ }^{29}$ Nevertheless, ongoing phase III studies are currently testing cisplatin, especially as induction chemotherapy before formal chemoradiotherapy (ACT II by UKCCCR; EORTC 22001/400014; and French Federation Nationale des Centres de Lutte Contre le Cancer, FNCLCC ACCORD03-study). Hopefully these studies will define the potential role of cisplatin in the future management of anal canal SCC. In addition, ongoing phase II trials are focusing on treating HIV-positive patients with anti-EGFR agents in an effort to reduce toxicity in this group who are particularly susceptible to complications. Furthermore, a study is currently being conducted by the MD Anderson Cancer Center testing oral capecitabine instead of 5FU. ${ }^{33}$ Therefore, the current recommendation for initial treatment of SCC of the anal canal remains chemoradiotherapy using regimes based on the chemotherapeutic agents, mitomycin and 5-FU.
After initial chemoradiation, SCC regression is slow and thus follow-up should start 6 to 12 weeks after the completion of the treatment. Recommendations for follow-up include digital rectal examination, anoscopy, inguinal lymph node palpation, and thoracoabdominal CT scan, especially for more advanced disease, every 3 to 6 months. Even though digital rectal examination alone might miss early local recurrences, controversy persists concerning the use of multiple random biopsies of normal-appearing tissue versus biopsy limited to suspicious lesion only. ${ }^{34}$ Some centers advocate the use of endoanal ultrasound (ERUS) especially three-dimensional (3D) modality to assess the entire full thickness of the anal canal wall. ${ }^{35}$

\section{SURGERY FOR ANAL CANAL SQUAMOUS CELL CARCINOMA}

Although no longer considered the primary treatment modality for anal canal cancer, surgery still has an important role in the treatment strategy. Initial examination under anesthesia and biopsy is required for the full assessment of many tumors. Second, temporary stoma formation (loop colostomy or ileostomy) is required in many cases for patients who cope poorly with the acute toxicity of radiotherapy or are at risk of developing a rectovaginal fistula. Furthermore, patients who have impairment of continence because of sphincter invasion should be defunctioned prior to radiotherapy. Third, surgery for clinically palpable inguinal node disease is often necessary. Finally, surgery is an option for salvage of recurrent or residual primary tumor after treatment with chemoradiotherapy.

\section{TREATMENT OF RECURRENT DISEASE}

In patients presenting with suspicious or proven recurrent disease, full staging must be completed using CT and MRI of the chest abdomen and pelvis to assess the extent of disease. When findings from anatomic imaging are inconclusive, PET can be useful to distinguish tumor from treatment-related abnormalities. Biopsy of recurrent or residual disease is mandatory before embarking on radical surgical resection. The classification of residual disease following chemoradiotherapy, and true recurrent disease is somewhat arbitrary, and most studies define residual tumor as disease present within 6 months of chemoradiotherapy and recurrent disease when a tumor is discovered after 6 months. In the majority of patients presenting with recurrent disease the median time to presentation is less than 12 months postchemoradiotherapy.

Following a comprehensive work-up to exclude extrapelvic disease, patients can be counseled about salvage surgery. The goal is to achieve negative margins around the tumor and therefore radical resection is frequently necessary. Most patients will undergo an abdominoperineal excision and permanent colostomy 
with creation of a large pelvic floor defect. Tumors that have invaded local structures such as the vagina or prostate should be resected with clear margins; this often involves multivisceral resection. The use of intraoperative radiotherapy or brachytherapy may improve local recurrence rates following radical resection where there is concern about an incomplete resection or close resection margins.

Most published series of outcomes following salvage surgery for SCC have small numbers of patients and the overall survival rate at 5 years following resection ranges from 30 to $64 \% .^{36-42}$ The most important prognostic factor of survival following resection is the status of the margin and patients with clear margins (R0) have up to a $75 \%$-year overall survival rate. ${ }^{42}$ Further predictors of a poor outcome following surgery are inguinal lymph node status, tumor size greater than $5 \mathrm{~cm}$, adjacent organ involvement, male gender, and higher comorbidities. ${ }^{36,41}$

In most series, the indication for salvage surgery is the persistence of tumor following chemoradiotherapy. ${ }^{36-42}$ Interestingly, these patients have a poor outcome following salvage surgery, even when resection is complete with negative margins. The 5-year survival rate following salvage surgery for persistent SCC following chemoradiation is 31 to $33 \%$ compared with 51 to $82 \%$ in those operated for true recurrence. ${ }^{36,39}$ It is felt that persistent tumors have a more aggressive tumor biology leading to worse outcomes following salvage surgery. The length of time to recurrence following salvage surgery varies from 1 to 50 months and is seen most commonly locally in $40 \%$ patients, in the inguinal node in $30 \%$, and in distant organs in $30 \% .^{38,41-43}$

Salvage surgery is associated with substantial morbidity in up to $72 \%$ of patients, due to delayed perineal wound healing, pelvic abscess, perineal wound hernia, urinary retention, and impotence. ${ }^{41}$ The poor perineal wound healing is as a result of the large defect created to fully excise these low tumors combined with prior radiotherapy received. Primary closure alone produces poor results when not combined with some type of flap procedure. In a series of 22 undergoing salvage APR treated with primary closure, $59 \%$ had perineal wound breakdown, 1 patient needed a reconstructive operation. ${ }^{43}$ Commonly used tissue flaps include the pedicled omental flap and the vertical rectus abdominis myocutaneous flap (VRAM). In 95 patients undergoing salvage APR, a comparison of pedicled omental flap to VRAM found less perineal wound complications and faster healing when the VRAM was used. ${ }^{44}$ There was no difference in abdominal wall hernia, but less perineal hernia after using VRAM compared with the pedicled omental flap. In another series of 18 patients, the perineal wound breakdown rate was $36 \%$ in patients undergoing omental flap reconstruction versus $0 \%$ in patients having their perineal floor reconstructed with
VRAM flap following salvage APR. ${ }^{37} \mathrm{~A}$ final series of 48 patients undergoing salvage APR reported no delayed wound healing or infectious complications when a VRAM flap was used. ${ }^{42}$ Therefore, in patients that undergo salvage surgery for persistent or recurrent SCC of the anal canal to reduce the complications of delayed perineal wound closure created by radiation and radical surgery, a surgical strategy of using a VRAM flap provides the optimal defect closure with lowest complications.

In summary, salvage surgery is the treatment of choice for residual and recurrent tumors in patients with failed primary chemoradiotherapy of anal canal SCC. A substantial portion of patients will be cured of their disease and outcomes can be optimized by careful selection of patients that will have negative margins following radical surgery.

\section{Adenocarcinoma}

Adenocarcinoma of the anal canal accounts for 3 to $9 \%$ of all anal canal neoplasms. ${ }^{1,45}$ Differentiating true anal canal adenocarcinoma from low rectal adenocarcinoma can be challenging. Most anal canal adenocarcinomas originate from anal glands, but cases developing in chronic tracts from fistula in ano are described. ${ }^{45}$ Multiple factors, including infection with HPV and HIV, history of receptive anal intercourse, smoking, and immunosuppression have been identified as risk factors. Clinical features include anal pain, induration of the anal canal, or abscess formation and a palpable lump. Evidence for treatment recommendations is based on small series and extrapolation from experience treating low rectal adenocarcinoma. Wide local excision can be performed for small well-differentiated tumors; however, APR in combination with neoadjuvant chemoradiation should be used for lesions greater than $2 \mathrm{~cm}$ in size (T2). ${ }^{46,47}$ Reported disease-free 5 -year survival varies from 21 to $58 \%$ according to the treatment modality and local recurrences rates range from 20 to $37 \%$ at 4 years. ${ }^{48,49}$

\section{ANAL MARGIN TUMORS}

\section{Paget's Disease}

Paget's disease was initially described in association with breast carcinoma. Extramammary Paget's disease can be found in various locations, including the anogenital region, where apocrine glands are found. Median age of presentation is 60 years and patients typically complain of anal pruritus, bleeding, and discharge. Macroscopically, anal margin Paget's disease presents as an erythematous and eczematous rash similar to benign skin conditions or other perianal diseases such as Bowen's disease, hydradenitis suppurativa, pruritus ani, or 
Crohn's disease. ${ }^{1,2}$ Diagnosis should be based on skin biopsies. Histologically, Paget's disease is commonly described as an intraepithelial adenocarcinoma characterized by presence of typical Paget cells, appearing as large rounded vacuolated cells.

Approximately $50 \%$ of patients with anal margin Paget's disease harbor a colorectal neoplasm mandating full colonoscopy for complete evaluation. ${ }^{50}$ Full assessment of the patient includes random mapping biopsies of the entire anal margin to evaluate superficial spread of disease that is often macroscopically not evident. ${ }^{1,51}$ Some advocate the use of preoperative biopsies performed under local anesthesia. ${ }^{2}$ In that way, pathologic diagnostic uncertainties that might occur on intraoperative frozen sections will be avoided. Preoperative planning of surgical resection margins should allow for a 1$\mathrm{cm}$ rim of normal tissue and histologic analysis with immunostaining gives reliable information. ${ }^{52}$ Once the extent of Paget's disease has been clearly demarcated, wide local excision is the procedure of choice. , $^{1,251,53-55}$ The skin defect can sometimes be too large for primary wound closure and myocutaneous or cutaneous flaps will be necessary. In a series of 27 patients, the recurrence rate after WLE was $30 \% .^{53}$ An invasive component was present in $44 \%$ of the patients, which was associated with poor prognosis. Chemoradiotherapy was used in 6 of 27 patients and 6 of 27 patients required a colostomy. The overall and disease-free survival rate at 5 years was $59 \%$ and 64\%, respectively. In the Mayo Clinic series, the recurrence rate was also high with $61 \%$ at 5 years and an overall 5-year survival rate was $67 \%$. The authors concluded that anal margin Paget's disease, despite high local recurrence rate, was not a systemically aggressive disease. This high recurrence rate and the high incidence of associated neoplasm in a patient with Paget's disease should nevertheless prompt vigilant long-term followup. ${ }^{1,56,57}$ When extensive locally invasive lesions, or a synchronous anorectal adenocarcinoma, are discovered, APR is indicated and the patient should receive neoadjuvant chemoradiotherapy to optimize outcome. ${ }^{1,51}$

Functional outcomes, especially in patients who needed repair of large perineal skin defects after wide excision, must be carefully considered. In a single study, overall quality of life (QOL) was similar to the normative population although a large proportion of patients ( 9 of 14) complained of some form of incontinence that impacted the gastrointestinal aspects of their QOL. ${ }^{58}$ In an effort to limit radical resection for anal Paget's disease, noninvasive treatments have been proposed with encouraging results and including photodynamic therapy, radiation therapy, systemic and topical chemotherapy. ${ }^{54,59,60}$

\section{Bowen's Disease}

Bowen's disease is synonymous with AIN 3 and when demonstrated on pathology indicates carcinoma in situ.
The causative agent is HPV, but only the 16 and 18 HPV genotypes are associated with high-grade AIN. ${ }^{12,61,62}$ Patients with anal margin Bowen's disease typically present with minor symptoms, such as burning or pruritus. Up to a third of the patients complain of a mass or bleeding lesion. ${ }^{62}$ Clinically, Bowen's disease presents as discrete, erythematous, occasionally brownred pigmented, noninfiltrating, scaly, or crusted plaques, which sometimes have a moist surface or even nodules. Differential diagnosis may be extensive and confusion with different benign dermatologic conditions like psoriasis, eczema, or leukoplakia is common. ${ }^{1,2}$ The standard treatment is wide surgical excision. ${ }^{63}$ To ensure clear resection margins, a systematic four-quadrant biopsy technique, with intraoperative frozen sections has been advocated. ${ }^{12}$ The frozen sections should include intraanal biopsies. Despite use of this technique, recurrence rates up to $30 \%$ have been reported. ${ }^{12,57}$ The major disadvantage of wide local excision is the difficulty to primarily close the wound and skin flaps may be necessary. The rotational $\mathrm{v}-\mathrm{y}$ skin flap has been most frequently described in this setting. ${ }^{1}$ When surgery is not feasible or refused, other options are available such as topical chemotherapy (5-FU), immunomodulation (imiquimod), and phototherapy, although the latest guidelines favor radiotherapy. ${ }^{63}$

\section{Squamous Cell Carcinoma}

$\mathrm{SCC}$ of the anal margin is less common than anal canal SCC, but is the most frequent tumor of the anal margin. Bulky advanced tumors of the anal margin sometimes directly invade the canal making definitive diagnosis of origin difficult. In these circumstances, treatment is often designed similar to that for tumors of anal canal origin. In contrast, tumors that are limited to the anal margin will be treated similar to cutaneous SCC elsewhere on the body. ${ }^{1,2,64}$ Clinical presentations include pain, bleeding, palpable lump, and discharge. Typically, SCC of the anal margin appears as an ulcerated lesion with rolled everted edges. A significant number of patients are misdiagnosed with an anal fissure, fistula, eczema, or hemorrhoids; therefore a biopsy is recommended for any persistent anal margin lesion not responding to conservative therapy. ${ }^{1,2}$ When histology is obtained, precise staging will allow categorization for treatment recommendations and prognosis. The staging system is analogous to cutaneous SCC. ${ }^{65}$ As a first step, a digital rectal exam sometimes in the setting of EUA, will define the extent of local disease. The groin should always be examined looking for enlarged or suspicious inguinal lymph nodes. The incidence of metastatic lymph nodes is related to tumor size with $0 \%$ in tumors less than $2 \mathrm{~cm}, 23 \%$ of tumors 2 to $5 \mathrm{~cm}$ and $67 \%$ of tumors greater than $5 \mathrm{~cm}^{.6}$ 
Wide local excision (WLE) is adequate for favorable lesions analogous to resection of cutaneous SCC of other regions of the body. Favorable tumors are welldifferentiated $\mathrm{T} 1(<2 \mathrm{~cm})$ or T2 tumors for which a minimal negative margin of $1 \mathrm{~cm}$ can be obtained without compromising the anal sphincter. ${ }^{2,34,66}$ Approximately $60 \%$ of all anal margin tumors are amenable to treatment with local excision. The same subgroup of patients can be treated equally successfully with either local excision or radiotherapy. ${ }^{50,67}$ Patients that are treated initially with local excision can subsequently receive radiotherapy with good results if margins are positive or close. In a series of 45 patients with mainly T1-2 anal margin SCC, 65\% underwent local excision that was then followed by radiotherapy producing a 5year disease-free survival rate of $86 \% .{ }^{64}$ Almost half of this group had close or positive surgical margins following local excision. An additional 26 patients with mainly T2 tumors treated with local excision and radiotherapy, or radiotherapy alone, had a 5-year survival rate of 88.3\%. Seven patients had a local recurrence that was successfully treated with abdominoperineal excision in five cases. ${ }^{68}$ Therefore, it would seem sensible that early $\mathrm{T} 1$ and T2 lesions can be safely treated with local excision. If there is concern about the excision margins, then radiotherapy can be added to produce a similar outcome. If a large skin defect persists after excision it can be covered by a rotational skin flap or a split skin graft.

For patients with larger tumors, nodal involvement, or invasion of the sphincter muscle, treatment with chemoradiotherapy is preferred. In cases of unfavorable SCC (poorly differentiated, large bulky tumors), more aggressive abdominoperineal resection does not surpass WLE in terms of local and distal control with local recurrences after APR reported as high as $63 \% .{ }^{66}$ For these lesions chemoradiotherapy, similar to the regimen used for anal canal SCC, is the appropriate treatment providing local disease control ranging from 60 to $100 \%{ }^{2,69}$ Inguinal nodes should always be part of the irradiation field for unfavorable tumors because of the risk of metastasis. Prophylactic inguinal irradiation is well tolerated and omission of groin irradiation can lead to regional or distal recurrence. ${ }^{66}$ For persisting tumor following chemoradiation or where disease locally recurs, salvage surgery achieves good local control with reasonable survival. ${ }^{1,2,66}$

\section{Basal Cell Carcinoma}

Basal cell carcinoma (BCC) of the anal margin is extremely rare, accounting for $0.2 \%$ of all anorectal neoplasms. ${ }^{2}$ Of all cutaneous BCC, $0.27 \%$ are localized to the anal margin and genital area., ${ }^{9,70}$ The etiology is unclear because sun exposure is less likely to be reported by these patients. ${ }^{71,72}$ One important characteristic is the frequent association with other skin lesions and the diagnosis should always prompt a thorough clinical examination. ${ }^{2,71,72}$ Most patients are men in their sixties, and lesions are usually less than $2 \mathrm{~cm}^{2}$ The risk of distant spread is very low. ${ }^{1,2}$ Wide local excision, with skin grafting if necessary, is the treatment of choice and has good long-term results. In the two largest series available, recurrence occurred in 0 to $29 \%$ of patients and the 5 -year cancer-specific survival rate was $100 \% .^{70,72}$ Deep invasion of the anal canal may mandate abdominoperineal resection, but this is an extremely unusual finding. Local recurrence can be treated by either reexcision or radiotherapy.

\section{Melanoma}

Malignant melanoma of the anal margin is a rare condition and accounts for 2 to $4 \%$ of all malignant anorectal neoplasms. It is the third most common site after skin and the eye and represents 0.6 to $1.6 \%$ of all melanomas. ${ }^{1,9}$ Symptoms are nonspecific with bleeding, pain, and mass being commonly reported. When a lesion is pigmented, melanoma is often suspected although confusion with thrombosed hemorrhoids is reported. ${ }^{2}$ Amelanotic lesions consist of $30 \%$ of the lesions and are more difficult to recognize, their diagnosis depends on demonstration of melanin pigment by immunohistochemistry. ${ }^{9}$

The surgical treatment of anal melanoma is typically wide local excision unless patients have extensive sphincter involvement and are incontinent. Overall prognosis is poor no matter the surgical approach and efforts to improve survival with radical resection, including APR, have not shown benefit. Data from the Surveillance, Epidemiology, and End Results (SEER) database confirms that the majority of these lesions are locally excised in U.S. centers. In this large series of 183 patients, median age at diagnosis was 68 years. Median survival rate for anal melanoma was independent of mode of surgical excision: 16 months for APR and 18 months for local excision. Moreover, the 5-year survival rate was similar in the two groups: $16.8 \%$ for APR and $19.3 \%$ for local excision. ${ }^{73}$ The absence of benefit of radical excision has been confirmed by other retrospective series and meta-analysis. ${ }^{74-77}$ Data from Memorial Sloan-Kettering has shown no difference between local excision and APR reporting a diseasespecific survival rate of $\sim 30 \%$ in both groups. The majority of patients in this series experienced distant metastatic disease: 13 with distant metastasis, 9 with both distant and locoregional, and 12 with locoregional recurrence. The authors hypothesize that systemic dissemination is an early event in the natural course of the disease and thus efforts should be focused on multimodal treatment. ${ }^{78}$ It appears that the only benefit of radical surgery is to obtain clear margins in tumors that are 
particularly bulky or invading the sphincter - here APR remains a viable option not only for local tumor control but for quality of life. ${ }^{1,9}$

\section{CONCLUSION}

Neoplasms of the anal canal and skin are uncommon and few physicians will be exposed to these lesions. Diagnosis and management is challenging in that signs and symptoms of neoplastic lesions often mimic benign conditions. This, coupled with many patients' reluctance to see a physician for anorectal complaints, may lead to misdiagnosis and delays in appropriate treatment. A thorough history targeted at risk factors, combined with a detailed examination under anesthesia, which includes biopsy, are necessary for correct diagnosis and planning for treatment of these tumors. Early diagnosis and appropriate oncologic directed intervention can lead to favorable outcomes in many patients.

\section{REFERENCES}

1. Nivatvongs S. Perianal and anal canal neoplasms. In: Gordon $\mathrm{PH}$, Nivatvongs S, eds. Colon, Rectum and Anus. $3^{\text {rd }}$ ed. New York, NY: Informa Healthcare; 2007:369-390

2. Welton ML, Varma MG. Anal cancer. In: Wolff BG, Fleshman JW, Beck DE, Pemberton JH, Wexner SD, eds. The ASCRS Textbook of Colon and Rectal Surgery. $1^{\text {st }}$ ed. New York, NY: Springer; 2007:482-500

3. Lengelé B, Scalliet P. Anatomical bases for the radiological delineation of lymph node areas. Part III: pelvis and lower limbs. Radiother Oncol 2009;92(1):22-33

4. Fenger DFM, Marti MC. Tumors of the anal canal. In: Hamilton SR, Aaltonen AL, ed. Pathology and Genetics of Tumors of the Digestive System. Lyon, France. IARC Press; 2000

5. Fenger C, Nielsen VT. Intraepithelial neoplasia in the anal canal. The appearance and relation to genital neoplasia. Acta Pathol Microbiol Immunol Scand [A] 1986;94(5):343-349

6. Horner M, Ries L, Krapcho M, et al. SEER Cancer Statistics Review 1975-2006. Bethesda, MD: National Cancer Institute; 2007

7. Altekruse SF, Kosary CL, Krapcho M, et al. SEER Cancer Statistics Review 1975-2007. Available at:http://seer.cancer. gov/csr/1975_2007/. Accessed August 25, 2010

8. Edge SB, Byrd DR, Compton CC, et al. Anus. In: AJCC Cancer Staging Manual. New York, NY: American Joint Committee on Cancer and Springer; 2010:165-173

9. Garrett K, Kalady MF. Anal neoplasms. Surg Clin North Am 2010;90(1):147-161

10. Franceschi S, De Vuyst H. Human papillomavirus vaccines and anal carcinoma. Curr Opin HIV AIDS 2009;4(1):57-63

11. Frisch M, Glimelius B, van den Brule AJ, et al. Sexually transmitted infection as a cause of anal cancer. N Engl J Med 1997;337(19):1350-1358

12. Marchesa P, Fazio VW, Oliart S, Goldblum JR, Lavery IC. Perianal Bowen's disease: a clinicopathologic study of 47 patients. Dis Colon Rectum 1997;40(11):1286-1293
13. Marfing TE, Abel ME, Gallagher DM. Perianal Bowen's disease and associated malignancies. Results of a survey. Dis Colon Rectum 1987;30(10):782-785

14. Hoots BE, Palefsky JM, Pimenta JM, Smith JS. Human papillomavirus type distribution in anal cancer and anal intraepithelial lesions. Int J Cancer 2009;124(10):2375-2383

15. Palefsky JM, Holly EA, Ralston ML, Greenblatt RM, Greenblatt RM; Da Costa M. Prevalence and risk factors for anal human papillomavirus infection in human immunodeficiency virus (HIV)-positive and high-risk HIV-negative women. J Infect Dis 2001;183(3):383-391

16. Penn I. Cancers of the anogenital region in renal transplant recipients. Analysis of 65 cases. Cancer 1986;58(3):611-616

17. Daling JR, Sherman KJ, Hislop TG, et al. Cigarette smoking and the risk of anogenital cancer. Am J Epidemiol 1992; 135(2):180-189

18. Frisch M. On the etiology of anal squamous carcinoma. Dan Med Bull 2002;49(3):194-209

19. Ryan DP, Compton CC, Mayer RJ. Carcinoma of the anal canal. N Engl J Med 2000;342(11):792-800

20. Gerard JP, Chapet O, Samiei F, et al. Management of inguinal lymph node metastases in patients with carcinoma of the anal canal: experience in a series of 270 patients treated in Lyon and review of the literature. Cancer 2001;92(1):77-84

21. Keightly M, Williams N. Malignant tumours of the anal canal and anus. In: Surgery of the Anus, Rectum and Colon. 3rd ed. Philadelphia, PA: Saunders; 2008:567-590

22. Damin DC, Rosito MA, Schwartsmann G. Sentinel lymph node in carcinoma of the anal canal: a review. Eur J Surg Oncol 2006;32(3):247-252

23. Mistrangelo M, Pelosi E, Bellò M, et al. Comparison of positron emission tomography scanning and sentinel node biopsy in the detection of inguinal node metastases in patients with anal cancer. Int J Radiat Oncol Biol Phys 2010; 77(1):73-78

24. Clark MA, Hartley A, Geh JI. Cancer of the anal canal. Lancet Oncol 2004;5(3):149-157

25. Boman BM, Moertel CG, O'Connell MJ, et al. Carcinoma of the anal canal. A clinical and pathologic study of 188 cases. Cancer 1984;54(1):114-125

26. Nigro ND, Vaitkevicius VK, Considine B Jr. Combined therapy for cancer of the anal canal: a preliminary report. Dis Colon Rectum 1974;17(3):354-356

27. UKCCCR Anal Cancer Trial Working Party. UK Coordinating Committee on Cancer Research. Epidermoid anal cancer: results from the UKCCCR randomised trial of radiotherapy alone versus radiotherapy, 5-fluorouracil, and mitomycin. Lancet 1996;348(9034):1049-1054

28. Northover J, Glynne-Jones R, Sebag-Montefiore D, et al. Chemoradiation for the treatment of epidermoid anal cancer: 13-year follow-up of the first randomised UKCCCR Anal Cancer Trial (ACT I). Br J Cancer 2010;102(7):1123-1128

29. Ajani JA, Winter KA, Gunderson LL, et al. Fluorouracil, mitomycin, and radiotherapy vs fluorouracil, cisplatin, and radiotherapy for carcinoma of the anal canal: a randomized controlled trial. JAMA 2008;299(16):1914-1921

30. Bartelink H, Roelofsen F, Eschwege F, et al. Concomitant radiotherapy and chemotherapy is superior to radiotherapy alone in the treatment of locally advanced anal cancer: results of a phase III randomized trial of the European Organization for Research and Treatment of Cancer Radiotherapy and Gastrointestinal Cooperative Groups. J Clin Oncol 1997; 15(5):2040-2049 
31. Flam M, John M, Pajak TF, et al. Role of mitomycin in combination with fluorouracil and radiotherapy, and of salvage chemoradiation in the definitive nonsurgical treatment of epidermoid carcinoma of the anal canal: results of a phase III randomized intergroup study. J Clin Oncol 1996; 14(9):2527-2539

32. Das P, Bhatia S, Eng C, et al. Predictors and patterns of recurrence after definitive chemoradiation for anal cancer. Int J Radiat Oncol Biol Phys 2007;68(3):794-800

33. Czito BG, Willett CG. Current management of anal canal cancer. Curr Oncol Rep 2009;11(3):186-192

34. Fleshner PR, Chalasani S, Chang GJ, Levien DH, Hyman NH, Buie WD; Standards Practice Task Force, American Society of Colon and Rectal Surgeons. Practice parameters for anal squamous neoplasms. Dis Colon Rectum 2008; 51(1):2-9

35. Christensen AF, Nyhuus B, Nielsen MB. Interobserver and intraobserver variation of two-dimensional and three-dimensional anal endosonography in the evaluation of recurrent anal cancer. Dis Colon Rectum 2009;52(3):484-488

36. Akbari RP, Paty PB, Guillem JG, et al. Oncologic outcomes of salvage surgery for epidermoid carcinoma of the anus initially managed with combined modality therapy. Dis Colon Rectum 2004;47(7):1136-1144

37. Ferenschild FT, Vermaas M, Hofer SO, Verhoef C, Eggermont AM, de Wilt JH. Salvage abdominoperineal resection and perineal wound healing in local recurrent or persistent anal cancer. World J Surg 2005;29(11):1452-1457

38. Ghouti L, Houvenaeghel G, Moutardier V, et al. Salvage abdominoperineal resection after failure of conservative treatment in anal epidermoid cancer. Dis Colon Rectum 2005;48(1):16-22

39. Nilsson PJ, Svensson C, Goldman S, Glimelius B. Salvage abdominoperineal resection in anal epidermoid cancer. Br J Surg 2002;89(11):1425-1429

40. Renehan AG, Saunders MP, Schofield PF, O'Dwyer ST. Patterns of local disease failure and outcome after salvage surgery in patients with anal cancer. Br J Surg 2005;92(5): 605-614

41. Schiller DE, Cummings BJ, Rai S, et al. Outcomes of salvage surgery for squamous cell carcinoma of the anal canal. Ann Surg Oncol 2007;14(10):2780-2789

42. Sunesen KG, Buntzen S, Tei T, Lindegaard JC, Nørgaard $\mathrm{M}$, Laurberg S. Perineal healing and survival after anal cancer salvage surgery: 10-year experience with primary perineal reconstruction using the vertical rectus abdominis myocutaneous (VRAM) flap. Ann Surg Oncol 2009;16(1):68-77

43. Stewart D, Yan Y, Kodner IJ, et al. Salvage surgery after failed chemoradiation for anal canal cancer: should the paradigm be changed for high-risk tumors?. J Gastrointest Surg 2007;11(12):1744-1751

44. Lefevre JH, Parc Y, Kernéis S, et al. Abdomino-perineal resection for anal cancer: impact of a vertical rectus abdominis myocutaneus flap on survival, recurrence, morbidity, and wound healing. Ann Surg 2009;250(5):707-711

45. Colvin M, Delis A, Bracamonte E, Villar H, Leon LR Jr. Infiltrating adenocarcinoma arising in a villous adenoma of the anal canal. World J Gastroenterol 2009;15(28): 3560-3564

46. Chang GJ, Gonzalez RJ, Skibber JM, Eng C, Das P, Rodriguez-Bigas MA. A twenty-year experience with adenocarcinoma of the anal canal. Dis Colon Rectum 2009; 52(8):1375-1380
47. Kounalakis N, Artinyan A, Smith D, Mojica-Manoso P, Paz B, Lai LL. Abdominal perineal resection improves survival for nonmetastatic adenocarcinoma of the anal canal. Ann Surg Oncol 2009;16(5):1310-1315

48. Beal KP, Wong D, Guillem JG, et al. Primary adenocarcinoma of the anus treated with combined modality therapy. Dis Colon Rectum 2003;46(10):1320-1324

49. Belkacémi Y, Berger C, Poortmans P, et al; Rare Cancer Network. Management of primary anal canal adenocarcinoma: a large retrospective study from the Rare Cancer Network. Int J Radiat Oncol Biol Phys 2003;56(5): 1274-1283

50. Sahai A, Kodner IJ. Premalignant neoplasms and squamous cell carcinoma of the anal margin. Clin Colon Rectal Surg 2006;19(2):88-93

51. Minicozzi A, Borzellino G, Momo R, Steccanella F, Pitoni F, de Manzoni G. Perianal Paget's disease: presentation of six cases and literature review. Int J Colorectal Dis 2010;25(1): $1-7$

52. Beck DE, Fazio VW. Perianal Paget's disease. Dis Colon Rectum 1987;30(4):263-266

53. McCarter MD, Quan SH, Busam K, Paty PP, Wong D, Guillem JG. Long-term outcome of perianal Paget's disease. Dis Colon Rectum 2003;46(5):612-616

54. Mirer E, El Sayed F, Ammoury A, Lamant L, Messer L, Bazex J. Treatment of mammary and extramammary Paget's skin disease with topical imiquimod. J Dermatolog Treat 2006;17(3):167-171

55. Sarmiento JM, Wolff BG, Burgart LJ, Frizelle FA, Ilstrup DM. Paget's disease of the perianal region—an aggressive disease? Dis Colon Rectum 1997;40(10):1187-1194

56. Marchesa P, Fazio VW, Oliart S, Goldblum JR, Lavery IC, Milsom JW. Long-term outcome of patients with perianal Paget's disease. Ann Surg Oncol 1997;4(6):475-480

57. Sarmiento JM, Wolff BG, Burgart LJ, Frizelle FA, Ilstrup DM. Perianal Bowen's disease: associated tumors, human papillomavirus, surgery, and other controversies. Dis Colon Rectum 1997;40(8):912-918

58. Conklin A, Hassan I, Chua HK, et al. Long-term functional and quality of life outcomes of patients after repair of large perianal skin defects for Paget's and Bowen's disease. J Gastrointest Surg 2009;13(5):951-955

59. Runfola MA, Weber TK, Rodriguez-Bigas MA, Dougherty TJ, Petrelli NJ. Photodynamic therapy for residual neoplasms of the perianal skin. Dis Colon Rectum 2000;43(4): 499-502

60. Vereecken P, Awada A, Ghanem G, et al. A therapeutic approach to perianal extramammary Paget's disease: topical imiquimod can be useful to prevent or defer surgery. Med Sci Monit 2007;13(6):CS75-CS77

61. Cleary RK, Schaldenbrand JD, Fowler JJ, Schuler JM, Lampman RM. Perianal Bowen's disease and anal intraepithelial neoplasia: review of the literature. Dis Colon Rectum 1999;42(7):945-951

62. Margenthaler JA, Dietz DW, Mutch MG, Birnbaum EH, Kodner IJ, Fleshman JW. Outcomes, risk of other malignancies, and need for formal mapping procedures in patients with perianal Bowen's disease. Dis Colon Rectum 2004; 47(10):1655-1660, discussion 1660-1661

63. Cox NH, Eedy DJ, Morton CA; Therapy Guidelines and Audit Subcommittee, British Association of Dermatologists. Guidelines for management of Bowen's disease: 2006 update. Br J Dermatol 2007;156(1):11-21 
64. Khanfir K, Ozsahin M, Bieri S, Cavuto C, Mirimanoff RO, Zouhair A. Patterns of failure and outcome in patients with carcinoma of the anal margin. Ann Surg Oncol 2008;15(4): 1092-1098

65. Edge SB, Byrd DR, Compton CC, et al. Cutaneous squamous cell carcinoma and other cutaneous carcinomas. In: AJCC Cancer Staging Manual. New York, NY: American Joint Committee on Cancer and Springer; 2010:301-314

66. Newlin HE, Zlotecki RA, Morris CG, Hochwald SN, Riggs $\mathrm{CE}$, Mendenhall WM. Squamous cell carcinoma of the anal margin. J Surg Oncol 2004;86(2):55-62, discussion 63

67. Fuchshuber PR, Rodriguez-Bigas M, Weber T, Petrelli NJ. Anal canal and perianal epidermoid cancers. J Am Coll Surg 1997;185(5):494-505

68. Chapet O, Gerard JP, Mornex F, et al. Prognostic factors of squamous cell carcinoma of the anal margin treated by radiotherapy: the Lyon experience. Int J Colorectal Dis 2007;22(2):191-199

69. Bieri S, Allal AS, Kurtz JM. Sphincter-conserving treatment of carcinomas of the anal margin. Acta Oncol 2001;40(1):29-33

70. Gibson GE, Ahmed I. Perianal and genital basal cell carcinoma: a clinicopathologic review of 51 cases. J Am Acad Dermatol 2001;45(1):68-71

71. Nielsen OV, Jensen SL. Basal cell carcinoma of the anus-a clinical study of 34 cases. Br J Surg 1981;68(12):856-857
72. Paterson CA, Young-Fadok TM, Dozois RR. Basal cell carcinoma of the perianal region: 20-year experience. Dis Colon Rectum 1999;42(9):1200-1202

73. Iddings DM, Fleisig AJ, Chen SL, Faries MB, Morton DL. Practice patterns and outcomes for anorectal melanoma in the USA, reviewing three decades of treatment: is more extensive surgical resection beneficial in all patients?. Ann Surg Oncol 2010;17(1):40-44

74. Kiran RP, Rottoli M, Pokala N, Fazio VW. Long-term outcomes after local excision and radical surgery for anal melanoma: data from a population database. Dis Colon Rectum 2010;53(4):402-408

75. Bullard KM, Tuttle TM, Rothenberger DA, et al. Surgical therapy for anorectal melanoma. J Am Coll Surg 2003; 196(2):206-211

76. Thibault C, Sagar P, Nivatvongs S, Ilstrup DM, Wolff BG. Anorectal melanoma-an incurable disease? Dis Colon Rectum 1997;40(6):661-668

77. Weyandt GH, Eggert AO, Houf M, Raulf F, Bröcker EB, Becker JC. Anorectal melanoma: surgical management guidelines according to tumour thickness. $\mathrm{Br} \mathrm{J}$ Cancer 2003;89(11):2019-2022

78. Yeh JJ, Shia J, Hwu WJ, et al. The role of abdominoperineal resection as surgical therapy for anorectal melanoma. Ann Surg 2006;244(6):1012-1017 